\title{
HumanizaSUS e a garantia do Princípio da Integralidade
}

\author{
HumanizaSUS and the guarantee of the Principle of Integrality \\ HumanizaSUS y la garantía del Principio de Integridad
}

Karina de Morais Gomes ${ }^{1}$

\begin{abstract}
RESUMO: objetivo: faz uma breve reflexão sobre a importância da humanização e sua incorporação no atual sistema de saúde brasileiro. Metodologia: A pesquisa foi realizada por meio de revisão bibliográfica, utilizando-se livros, e artigos científicos na base de pesquisa SCIELO Brasil e BVS complementada pela realização de uma entrevista com o Coordenador Nacional da Política Nacional de Humanização da Atenção e Gestão em Saúde. Resultados: Aborda-se como esta política pública de saúde pode contribuir para a efetivação dos princípios constitucionais referentes ao direito à saúde, em especial, o direito à atenção integral em saúde. São explanados aspectos da reforma sanitária brasileira, com especial foco na integralidade como um direito constitucional e um pouco da trajetória do direito à saúde. São abordados alguns conceitos sobre integralidade tanto em seu aspecto jurídico como sociológico, além de avaliar sua importância para nortear a construção de uma política pública. A Política Nacional de Humanização da Atenção e Gestão em Saúde é, segundo esta nossa perspectiva, um instrumento que pode ser utilizado para que o direito à assistência à saúde seja efetivado, respeitando parâmetros técnicos, bem como, as subjetividades de todos os atores envolvidos no processo assistencial: usuários, profissionais e gestores. Conclusão: a efetivação passa pelo reconhecimento da necessidade de conscientização, da superação de limites e barreiras, tendo como ponto chave a construção dialógica, acerca de quais mudanças precisam acontecer para que tenhamos um Sistema Único de Saúde cada vez melhor.
\end{abstract}

Palavras-chave: Humanização da Assistência. Reforma dos Serviços de Saúde. Integralidade em Saúde

ABSTRACT: objective: this article provides a brief reflection on the importance of humanization and its incorporation into the current Brazilian health system. Methods: The survey was conducted through literature review, using books, articles and scientific research base in SCIELO Brazil and BVS, complemented by conducting an interview with the National Coordinator of the National Policy on Humane Care and Management in Health is approached as this public health policy can contribute to the realization of the constitutional principles regarding the right to health and the right to comprehensive health care. Results: Are explained aspects of Brazilian health reform, with special focus on integrity as a constitutional right and a little history of the right to health. Some concepts are addressed both in its entirety on legal and sociological aspect, in addition to assessing their importance to guide the construction of a public policy. The National Policy on Humane Care and Health Management is, according to this our perspective, an instrument that can be used for the right to health care is finalized, respecting technical parameters as well as

\footnotetext{
${ }^{1}$ Biomédica formada pelo Centro Universitário de Brasília - UniCEUB. E-mail: karinademorais@gmail,com
} 
the subjectivity of all actors involved in care process: users, professionals and managers. Conclusion: This realization depends on the recognition of the need for awareness, overcoming boundaries and barriers, with the key point the dialogical construction, about what changes need to happen for us to have a Health System better.

Keywords: Humanization of Assistance. Health Care Reform. Integrality in Health.

RESUMEN: Objetivo: este artículo presenta una breve reflexión sobre la importancia de la humanización y su incorporación al actual sistema de salud brasileño. Metodología: La encuesta se realizó a través de la revisión de la literatura, utilizando libros, artículos y base de investigación científica en SCIELO Brasil e BVS complementada con una entrevista con la Coordinadora Nacional de la Política Nacional de Atención Humana y Gestión en Salud. Contribuir a la realización de los principios constitucionales relativos al derecho a la salud y al derecho a la atención integral de la salud. Resultados: Se explican aspectos de la reforma sanitaria brasileña, con especial atención a la integridad como derecho constitucional y un poco de historia del derecho a la salud. Algunos conceptos se abordan tanto en su totalidad en aspectos jurídicos y sociológicos, como en la evaluación de su importancia para orientar la construcción de una política pública. La Política Nacional de Atención Humana y Gestión de la Salud es, según nuestra perspectiva, un instrumento que puede ser utilizado para el derecho a la atención de la salud, con los parámetros técnicos y la subjetividad de todos los actores implicados en el proceso asistencial: Profesionales y gerentes. Conclusión: Esta toma de conciencia depende del reconocimiento de la necesidad de concienciación, superación de fronteras y barreras, con el punto clave de la construcción dialógica, sobre qué cambios deben realizarse para que tengamos un Sistema de Salud mejor.

Palabras Ilave: Humanización de la Asistencia. La reforma de salud. Integralidad en Salud.

\section{Introdução}

A garantia do direito à saúde e a configuração de uma política de proteção social em saúde abrangente (para todos e de forma igualitária) se configuraram muito recentemente apenas a partir da promulgação da Constituição Federal de 1988 (1) e da instituição do Sistema Único de Saúde (2). Esta política de proteção social em saúde abrangente denominada Sistema Único de Saúde (SUS) foi construída a partir de um processo de luta travada pelo movimento da Reforma Sanitária desde o final dos anos setenta, quando se iniciou a construção de um amplo consenso acerca dos princípios básicos que deveriam nortear a concretização do direito à saúde.

São princípios doutrinários que regem o SUS: a universalidade, a integralidade, a igualdade, e a participação da comunidade. A criação do SUS representou um avanço, especialmente, pelos seus princípios doutrinários que se traduzem na garantia de acesso 
de toda população aos serviços de saúde e participação dos cidadãos no processo de formulação de políticas de saúde e no controle da execução das mesmas. (3).

A Lei 8.080/90 (4) traz em seu texto a integralidade da assistência como um princípio e a descreve como "conjunto articulado e contínuo das ações e serviços preventivos e curativos, individuais e coletivos, exigidos para cada caso em todos os níveis de complexidade do sistema". Segundo Mattos (5), a integralidade é uma bandeira de luta e corresponde a um conjunto de valores pelos quais se deve lutar, uma vez que se relacionam a um ideal de sociedade mais justa e solidária.

É inegável que o Sistema Único de Saúde já é uma grande conquista, mas ainda vem lutando para conseguir superar muitos desafios que estão no seu caminho. O governo Federal tem lançado mão de diversas iniciativas para combater situações procrastinatórias, a saber: falta de atendimento, grandes filas, onde a classificação de risco não é respeitada, etc. Dentre essas iniciativas se inclui a Política Nacional de Humanização (PNH), que passou a orientar a humanização da saúde (6).

O HUMANIZASUS - Política Nacional de Humanização da Atenção e Gestão em Saúde traz como princípios a inseparabilidade da atenção e gestão em saúde; o estimulo à autonomia e protagonismo de todos os atores envolvidos (gestores, trabalhadores e usuários) e a transversalidade em todas as ações em saúde. (7). Assim, o tema Humanização visa acima de tudo reforçar a dignidade do profissional e do usuário. É uma busca pela qualificação desses profissionais, bem como, dos serviços prestados aos cidadãos. Humanizar é entender que cada pessoa deve ser tratada em sua singularidade, respeitando sua cultura, suas experiências enquanto individuo (8).

A reflexão humanística não enfoca somente problemas e necessidades biológicas, mas também abrange as circunstâncias sociais, éticas, educacionais e psíquicas presentes nos relacionamentos humanos existentes nas ações relativas à atenção em saúde. (9). O atendimento humanizado e integral deve ser oferecido desde o momento em que 0 cidadão entra em um serviço de saúde, seja ele de básica, média ou alta complexidade. Além dessa frente de atuação o Programa de Humanização diz respeito também às boas condições de trabalho aos profissionais, melhoria na remuneração, para que os mesmos tenham condições de fornecer atendimento digno e de qualidade à população.

Este trabalho tem como objetivo relacionar a Humanização com o direito à atenção integral em saúde, pois é de suma importância levantar reflexões que contribuam para o 
entendimento da Humanização como prática relevante no contexto atual, orientando as práticas de saúde entre os diversos atores sociais envolvidos.

Trata-se de um trabalho descritivo-analítico, onde será realizada uma pesquisa teórica. As informações levantadas foram obtidas por meio de pesquisa de artigos científicos e livros que abordam o tema da pesquisa, bem como de outros temas relacionados. No que tange às bibliografias utilizadas, os artigos se encontram nas bases de pesquisa SCIELO BRASIL e Biblioteca Virtual em Saúde do Ministério da Saúde - BVS. Inicialmente foram pesquisados 9 livros e 30 artigos, dos quais 18 serviram de embasamento teórico. Destes, 15 foram lidos na íntegra e os demais foram consultados a partir de seus resumos. As palavras-chave utilizadas para a realização da pesquisa foram integralidade, humanização e direito à saúde.

Além da pesquisa bibliográfica, foi realizada uma entrevista com o Dr. Gustavo Nunes Oliveira, que atualmente é Coordenador Nacional do HUMANIZASUS. O mesmo é formado em medicina pela Unicamp/SP, fez residência e especialização na área de saúde da família. Possui mestrado e doutorado em saúde coletiva e é professor adjunto do Departamento de Saúde Coletiva da Faculdade de Ciências da Saúde (DSC/FS) da Universidade de Brasília (UnB), estando cedido atualmente ao Ministério da Saúde (MS).

O artigo está organizado em três partes. Na primeira trataremos da reforma sanitária brasileira, com foco especial no princípio da integralidade, pois o direito constitucional à saúde pública possui a integralidade da assistência como diretriz prevista no artigo 198, inciso II, da Constituição Federal e como princípio expresso no artigo 7ํ, inciso II, da Lei 8.080 de 1990. Serão abordados alguns conceitos sobre integralidade inicialmente no seu aspecto jurídico e em seguida sociológico.

Na segunda parte, será exposta a trajetória da Política Nacional de Humanização e seus princípios. Na terceira, o esforço será no sentido de avaliar a importância da integralidade enquanto princípio constitucional e do HUMANIZASUS, bem como a potência deste para a efetivação do referido princípio.

\section{A centralidade da integralidade da assistência na reforma sanitária brasileira (RBS)}

A Reforma Sanitária Brasileira é uma quebra de paradigmas sobre como a sociedade deveria ter acesso aos benefícios sociais na área da saúde. (2). 
O direito à saúde pública encontra-se positivado na Constituição Federal expressamente nos artigos 6ำ 196: sendo um direito social e fundamental, é um dever do Estado. A saúde é inerente ao ser humano, bem como à sua vida com dignidade, sendo fundamento da República Federativa do Brasil, expresso na Constituição Federal em seu artigo $1^{\circ}$, inciso III.

O direito constitucional à saúde pública possui a integralidade de assistência como diretriz prevista no artigo 198, inciso II, da Constituição Federal e como princípio expresso no artigo 7ํㅜ inciso II, da Lei 8.080 de 1990. O direito à saúde pública é pautado na universalidade de cobertura e na integralidade de assistência. Diretriz consagrada pela Constituição de 1988, e a integralidade da assistência é um princípio básico da saúde pública, regulamentado na Lei 8.080 de 1990 em seu artigo $7^{\circ}$ :

Art. 7ํㅗ As ações e serviços públicos de saúde e os serviços privados contratados ou conveniados que integram o Sistema Único de Saúde (SUS), são desenvolvidos de acordo com as diretrizes previstas no art. 198 da Constituição Federal, obedecendo ainda aos seguintes princípios:

(...)

II - integralidade de assistência, entendida como conjunto articulado e contínuo das ações e serviços preventivos e curativos, individuais e coletivos, exigidos para cada caso em todos os níveis de complexidade do sistema; (4)

O termo integralidade é usado desde a metade do século $X X$, porém, até hoje não existe um consenso a respeito de sua definição, mas, diante da abrangência e amplitude de concepções concedidas à integralidade, é possível perceber sua relevância na operacionalização do SUS. Sua efetivação, entretanto, constitui um verdadeiro desafio para o sistema (10).

É importante ressaltar nesse contexto quais são os sentidos atribuídos à integralidade, para que seja possível identificar as marcas específicas das políticas e das práticas relacionadas à integralidade e assim, contribuir para a existência de certa especificidade na reforma sanitária brasileira e no projeto societário que a move (11).

Segundo Mattos (5), a integralidade não é apenas uma diretriz do SUS definida constitucionalmente. Ela é uma "bandeira de luta", parte de uma "imagem objetivo", um enunciado de certas características do sistema de saúde, de suas instituições e de suas práticas que são consideradas por alguns desejáveis. Ela tenta falar de um conjunto de 
valores pelos quais vale lutar, pois se relacionam a um ideal de uma sociedade mais justa e mais solidária.

Para Camargo Júnior (12), a palavra integralidade, no contexto brasileiro, não pode ser entendida como um conceito, mas sim como um agrupamento de tendências políticas com relação entre si, o que pode demonstrar tanto fragilidade como potencialidade para 0 tema. Nesta mesma linha, Conill (10) defende que predomina no Brasil a percepção ampliada de integralidade, com ênfase no caráter completo, contínuo e ordenado do cuidado.

De acordo com Mattos (5), existem três sentidos para melhor classificar e entender a integralidade. O primeiro sentido diz respeito à medicina integral, que trata das práticas profissionais, onde procura abranger as necessidades de saúde dos usuários dos serviços, buscando contemplar não só as necessidades relativas ao controle de doenças, mas também, aquelas do ser humano como um ser bio-psicossocial, contemplando também aspectos psicológicos, sociais e culturais. O segundo sentido está relacionado à integralidade nas políticas especificas, direcionadas a populações ou portadores de doenças especificas, como idosos, portadores de HIV, com o objetivo de atender as diversas dimensões envolvidas na questão. Por fim, o terceiro sentido está relacionado à integralidade na organização dos serviços, que trata da articulação e coordenação entre os serviços e a garantia da continuidade da assistência em redes organizacionais de atenção integral.

Para viabilizar o SUS na vida real, os gestores municipais, estaduais, e federais precisam investir na construção de Redes de Atenção à Saúde, tanto no território do município como no território regional, estadual, e nacional. Redes, em essência, correspondem à articulação entre serviços e sistemas de saúde, e às relações entre atores que aí atuam, mediante relações de interdependência entre os pontos da Rede. Os usuários do SUS devem ser conduzidos nestas Redes para buscar a Atenção a sua Saúde, e dependem da eficácia desta articulação para ter suas necessidades atendidas (13). Tal abordagem é um desafio ao nosso sistema, diante do modelo de médicocentrado, especializado, fragmentado e hospitalocêntrico.

Nos anos 70 e 80 questionava-se o modelo assistencial vigente, centrado no médico e em práticas curativas, onde se enfatizava a doença excluindo-se a promoção e a prevenção à saúde e configurando-se como um modelo desumano tanto pelo uso 
exagerado de tecnologias como pelo relacionamento entre os profissionais e os usuários do sistema (8).

A integralidade como conceito estrutural e constituinte nas práticas de produção do cuidado, obriga-nos a ter em vista um sistema de saúde centrado no cuidado ao usuário e busca uma visão direcionada à idéia da totalidade do sujeito, avesso à fragmentação (14). Algumas sugestões de mudanças envolvem o repensar na formação dos profissionais que ainda é focado no aprendizado técnico racional e individualizado (15). Outra mudança diz respeito aos serviços de saúde, possibilitando a construção de um projeto político que garanta a operacionalização dos serviços, valorizando a dignidade do usuário e do trabalhador.

Diante do exposto, fica evidente a necessidade de se buscar a formação de parcerias entre os órgãos da saúde. Tais parcerias ocorrem em diferentes níveis de complexidade: 0 primeiro é o reconhecimento do outro como par, com direito a emitir opiniões; o segundo é do conhecimento de quem é o outro e como vê o mundo; o terceiro é o da colaboração, com vínculos de reciprocidade; posteriormente, encontra-se o nível de cooperação, que implica a existência ou a identificação de um problema comum, com uma forma sistemática e estável de atividades; por fim, tem - se o nível de associação com contratos ou acordos e utilização conjunta de recursos (16).

Segundo Mattos (5), é importante que se faça uma reflexão sobre a noção de integralidade no contexto do debate sobre os rumos do Sistema Único de Saúde. As noções de integralidade, assim como os demais princípios e diretrizes do SUS, foram forjadas de um lugar de oposição, e de crítica radical às práticas, às instituições e à organização do sistema de saúde. A integralidade segue sendo um bom indicador da direção que desejamos imprimir ao sistema e suas práticas e, portanto, segue indicando aquilo que é criticável no sistema e nas práticas de saúde que ainda existem hoje.

\section{Humanizasus: trajetória e princípios}

No campo da saúde, o conceito de humanização surge com um princípio vinculado ao paradigma de direitos humanos. A fonte mais recente dos princípios da humanização pode ser encontrada na Declaração Universal dos Direitos do Homem, onde é fundamentada nas noções de dignidade e igualdade de todos os seres humanos (17): "Em outras 
palavras, o que é devido ao paciente como um ser humano, pelos médicos e pelo Estado, se conformou em grande parte devido a esta compreensão dos direitos básicos das pessoas" (18).

No Brasil, esta noção de dignidade, de respeito à vida humana ganhou, relevância a partir da década de 90 do século passado. As reivindicações e a legislação do paciente foram constituintes do processo de construção da democracia e da cidadania, tanto no plano do desenho institucional do Estado, como também da sociedade, através de suas associações e organizações (17). Surgiram os direitos individuais vinculados aos direitos sociais em saúde a partir da Constituição de 1988, que estabelece que os serviços de saúde, devem preservar a autonomia das pessoas e garantir que tenham acesso à informação sobre sua saúde (1). Foram elaboradas diversas leis e portarias estaduais e federais, que definiram uma série de direitos dos pacientes.

Em resposta à grande reivindicação em relação à humanização do atendimento por parte dos movimentos sociais, o Ministério da Saúde, criou em 2001 o Programa Nacional de Humanização da Assistência Hospitalar (PNHAH), que tinha como foco o hospital, campo de intervenção privilegiado, lugar de relações verticalizadas orientadas por normas que deveriam ser operacionalizadas na busca de realização de metas e índices, independentemente de sua resolutividade e qualidade (19). Surgiu como uma tentativa de enfrentar, a má qualidade nas diversas áreas do atendimento hospitalar, voltando-se para as necessidades dos usuários e profissionais (17).

O programa teve como objetivo a capacitação dos profissionais de saúde para atender as questões relacionadas à dimensão psicossocial dos usuários e de suas famílias. Incentivou o trabalho em equipe multiprofissional, compreendendo ser esta uma das condições fundamentais para a eficácia da prática humanizada, devido à grande especialização e tecnificação dos procedimentos realizados por profissionais de saúde e ao surgimento de novas formas organizacionais do trabalho, que resultam em progressivo afastamento dos profissionais de saúde em relação aos usuários, diminuindo cada vez mais o vínculo nas relações, tornando-as mais distantes, impessoais e sem personalidade (9).

Posteriormente, criada em 2003, a Política Nacional de Humanização (PNH) é uma iniciativa inovadora no SUS, tendo como objetivo qualificar práticas de gestão e de atenção em saúde. Uma missão desafiadora, uma vez que na perspectiva da humanização, isso 
corresponde à produção de novas atitudes por parte de trabalhadores, gestores e usuários, superando desafios do cotidiano do trabalho (7).

Caracteriza-se por sua proposta transversal e abrangente, configurando-se como um conjunto de princípios e diretrizes traduzidas em ações nas diversas práticas de saúde e esferas do sistema, não apenas na assistência hospitalar. Assim, é introduzida uma construção coletiva, acionando todos os envolvidos no campo da saúde (6). A PNH se propõe a um processo de criação que envolve tanto questões éticas, estéticas e política. "Ética porque implica mudança de atitudes dos usuários, dos gestores e trabalhadores de saúde, de forma a comprometê-los como co-responsáveis pela qualidade das ações e serviços gerados; estética por se tratar do processo de produção/criação da saúde e de subjetividades autônomas e protagonistas; política, porque diz respeito à organização social e institucional das práticas de atenção e gestão na rede do SUS” (6).

Segundo Nunes (20):

A PNH trabalha sob a égide dos princípios e diretrizes do SUS; então, aquilo que é principio e diretrizes do SUS são [também] orientações de referência ético-politicas de como o SUS deve funcionar. (...). Para isso acontecer, é preciso não só a gente dizer que esses princípios são importantes, mas a gente precisa dar forma concreta para eles acontecerem, é o que a gente chama de dispositivos.

Estes dispositivos da humanização são, segundo Santos Filhos (21), "os direcionadores ou os próprios equivalentes de intervenções." A Política de Humanização parte de conceitos e dispositivos de trabalho em saúde, propondo centralmente transformações nas relações sociais, que envolvem trabalhadores e gestores em sua experiência cotidiana de organização e condução de serviços; e transformações nas formas de produzir e prestar serviços à população.

A PNH define a humanização como uma maneira de fazer inclusão, como uma prática social ampliadora dos vínculos de solidariedade e mútua responsabilidade, uma prática que se estende seguindo o Método da Tríplice Inclusão. Dessa forma, o feito da humanização se faz pela inclusão, nos espaços da gestão, do cuidado e da formação, de sujeitos e coletivos, assim como, dos analisadores (as perturbações) que estas inclusões produzem. Ou seja, humanização é inclusão (13).

Os princípios da PNH são a indissociabilidade entre gestão e cuidado, a transversabilidade (ampliação da comunicação; produção do comum) e o fomento do 
protagonismo das pessoas. Deste modo, o exercício do método - a inclusão - deve se garantir, impreterivelmente, que não se afaste a gestão da clínica, que se estimulem processos de comunicação para além da hierarquia e do corporativismo, e que se aposte que os sujeitos são capazes de produzirem deslocamentos de seus interesses mais importantes, construindo processos de debates, permitindo a criação de meios de comunicação eficientes e projetos comuns. Porém, não basta incluir, é importante que esse processo seja orientado por princípios e diretrizes. Estas orientações são clínicas, políticas e éticas (7)

Kunkel (22) relata que a humanização da saúde está relacionada à cidadania. A mesma autora expõe aspectos que desumanizam as relações na saúde. Primeiramente, aponta a especialização que fragmenta o usuário e não contribui para um atendimento de qualidade. O segundo aspecto diz respeito â desumanização do atendimento, que se caracteriza pela assimetria entre usuário e profissional, pautada em uma situação de inferioridade do primeiro em relação ao segundo, com desconsideração de seus conhecimentos e de sua iniciativa. O terceiro ponto se configura, quando o atendimento de saúde é realizado com uma entrega pelo usuário - tornado paciente para o profissional de todo o conhecimento em relação do que se passa consigo. A situação passa a ter um domínio, pelas falas que supervalorizam o saber médico e desconsideram os modos de vida das pessoas. Por fim, a redução do usuário ao paciente organiza uma lógica pautada na doença, e não na sua identidade integral. A autora enfatiza ainda que humanizar o cuidado em saúde é combater as perspectivas que enganam o usuário e o destitui de informações de suma importância sobre sua saúde, desrespeitando a sua cultura e seus costumes. Segundo a autora, a saúde necessita estar referida ao modo de viver das pessoas e contextualizada na sociedade para estar comprometida com um processo de mudança.

Então, é nesse sentido que a gente coloca o papel da PNH: quando a gente diz que nossa diretriz é co-gestão, a gente está dizendo [que] para organizar o sistema de saúde, a gente deve organizar o modelo de gestão, a forma de organizar os serviços, organizar a relação entre trabalhadores e gestores de maneira democrática, de maneira colaborativa, que no campo da saúde, o resultado do trabalho é dependente do engajamento, inclusive, afetivo desejante do trabalhador, e para isso acontecer ele não pode estar alienado do trabalho, ele tem que ter identidade com o objeto de trabalho dele. Então, ele tem que considerar o usuário como um sujeito igual a ele e tem que considerar o gestor como um parceiro. Como ele vai fazer isso se os interesses forem diferentes? Criando espaços, onde se possa então 
negociar esses interesses, essas diversas racionalidades; que o gestor pensa diferente do trabalhador, que por sua vez pensa diferente do usuário; então, o colegiado é um espaço, por exemplo, onde essa cogestão pode acontecer concretamente e aquilo que é necessário acontecer para o serviço se organizar para dar conta da integralidade fica mais viável (20).

\section{Humanização e a necessidade de integrar}

O direito à saúde é um direito que está vinculado à solidariedade estatal, e além, deste vínculo, é um direito que está profundamente ligado à cidadania. Essa noção do direito à saúde é fruto da evolução do próprio conceito de "direito". Inicialmente, os direitos subjetivos (relacionados ao ser humano, considerado como individuo) eram nada mais que direitos unicamente abstratos (direito à vida, à livre expressão, ao exercício dos direitos do cidadão, etc.). Ao longo de dois séculos, surgiram os direitos que chamamos de segunda geração (direitos sociais, culturais e econômicos, bem como, os direitos coletivos ou de coletividade); posteriormente aqueles de terceira geração (direito à paz, á autodeterminação dos povos, ao meio ambiente, qualidade de vida, a utilização e conservação do patrimônio histórico e cultural e o direito à comunicação), principalmente os direitos sociais. As mudanças atuais da cidadania são devidas às mudanças de sentido de alguns conceitos das ciências jurídicas (23).

As novas condições de organização das ações de saúde no Brasil foram concretizadas a partir da regulamentação do SUS, na Constituição de 1988 e na legislação ordinária subseqüente (Lei 8.080/90 e Lei 8.142/90). A saúde como direito social é a mudança fundamental anunciada pelo SUS. Com isso, a nova arena exige mais. Tendo como base um conceito amplo sobre saúde, foi necessário que se criassem formas de materializar socialmente e politicamente uma ação de cuidado integral, como direito de cidadania (24).

A Constituição Federal de 1998 erigiu a saúde como direito de todos, criou para o Estado o dever de garantir ações e serviços de saúde por meio de políticas publicas. É por intermédio das políticas publicas que se busca a efetivação do acesso à saúde de maneira universal e igualitária. A competência para desenvolver políticas públicas do Poder Executivo, por meio da definição de prioridade e da escolha por meios para sua realização, e ao Poder Legislativo, por meio da elaboração de leis, inclusive orçamentárias (25). 
A saúde não é entendida somente como ausência de doença ou como "um estado de bem-estar": saúde é a capacidade de lutar contra tudo que agride a pessoa e a ameaça, inclusive a doença, e o atendimento humanizado de saúde deve fortalecer essa capacidade de luta (conceito ampliado de saúde) (22).

Quando se considera a amplitude do conceito de integralidade, pode parecer uma contradição ao que está escrito no texto constitucional: "Atendimento integral, com prioridade para as atividades preventivas, sem prejuízos dos serviços assistenciais" (1). A prioridade atribuída à prevenção tem uma forte conotação política, e leva em consideração a trajetória da atenção à saúde no Brasil. O texto constitucional busca resgatar a imensa dívida do sistema de saúde diante da prevenção das doenças da população brasileira. As organizações do setor sempre estiveram divididas entre ações médico-assistenciais e preventivas, o que ocasionou pesos distintos no sistema. Ressalta ainda que atualmente busca-se oferecer assistência integral através de uma maior articulação das práticas e tecnologias relacionadas ao conhecimento clínico e epidemiológico.

Uma mudança na saúde, mesmo que setorial, está permanentemente interagindo e dependente da disputa dos valores gerais na sociedade na qual se insere. Para todos os que têm divulgado propostas humanizadoras, há uma intenção de discutir e influenciar os rumos desse movimento, disputando a direção das transformações na área da saúde. Logo, esse movimento humanizador está propício a ganhar musculatura. Essa é uma tendência forte na área da saúde, pois toda assistência tem início nas relações interpessoais. A saúde particularmente depende dessas relações, para que os serviços relacionados à mesma sejam ofertados de forma eficaz. O usuário é de grande importância nessa relação, de tal modo, que ele é coparticipe do processo de trabalho e coresponsável pelo êxito da ação terapêutica (24).

Portanto, cada encontro entre uma pessoa e um profissional de saúde é de grande relevância para que seja produzido um cuidado integral, pois, de acordo com as características especificas do contexto desse encontro, é possível determinar ações voltadas para suprir as necessidades dessa pessoa. (5). A integralidade retomada nas discussões atuais reafirma vários temas que a PNH lembra como princípios. A diferença talvez esteja no fato de que o princípio da integralidade está no texto constitucional, no capítulo da saúde, enquanto a humanização surge como uma tendência das últimas décadas. (26). 
O conceito de integralidade se direciona, portanto, à produção de saúde, e não apenas ao tratamento. O foco recai sobre os trabalhadores e seus processos de trabalho e qualificação profissional. E se o ponto de partida for a humanização, é preciso dizer que o trabalho constitui elemento que significa a dimensão humana no sentido do reconhecimento, produção e realização profissional. A PNH ressalta a importância da reflexão dos trabalhadores, incentivando seu potencial criativo, de superar imprevistos, a fim de transformar, o que a princípio, seria adverso contra si próprio, em um instrumento a seu favor (7).

Segundo Nunes (20):

$\mathrm{Na}$ saúde, se o trabalhador é tratado como um trabalhador de linha de montagem, ele não consegue se identificar (...). Marx falava, que (...), se o trabalhador não se identifica com a obra que ele produz, ele se aliena do processo de trabalho, ele se desapropria do objeto de desejo, ai ele só trabalha para ganhar dinheiro e vai viver a vida dele em outro lugar. Quando a gente faz isso na saúde, isso gera banalização do sofrimento. Em geral, o usuário não é usuário, é paciente, ele é um poliqueixoso, ele é o cara que está reclamando, então isso é o que a gente chama de alienação do trabalho no campo da saúde. Quando a gente vai enfrentar isso, estamos enfrentando uma tradição histórica, então quando a gente diz assim, 'olha trabalhador você precisa participar do processo de trabalho, 'olha gestor os trabalhadores precisam participar da organização do próprio processo de trabalho, isso produz melhores práticas de saúde', 'olha usuário você precisa participar da gestão do serviço de saúde, porque nós estamos trabalhando aqui a gestão participativa, então nós queremos ouvir você.

O que acontece (20) quando a gente consegue produzir isso, é que os serviços melhoram muito, as condições de trabalho melhoram, o gestor se sente menos isolado e os resultados melhoram (...) os dispositivos têm esse nome dispositivo por conta disso: quando eu reúno lá uma equipe de trabalho que nunca consegue se reunir, nunca discute caso e está trabalhando cada um em seu consultório, atendendo ficha, ele não está atendendo as pessoas, está atendendo fichas, e a gente propõe 'olha, vamos discutir um caso', a primeira reação é, 'olha, não dá, tenho um monte de pacientes para atender'. Quando a gente diz, e faz um acordo com a gestão, 'vamos sentar para discutir um caso por semana', e a gente começa a fazer isso, os trabalhadores adoram, porque a gente aprende na escola que sentar e discutir caso é uma coisa enobrecedora, interessante, que nos qualifica, então tem um valor de uso. Aí, o primeiro sucesso é a gente sentar e discutir um caso, então a gente fez com uma equipe que nunca se reuniu, se reunir e pensar junto sobre uma coisa que pode ser muito simples, mas isso funciona como um dispositivo, aí isso funciona como uma vivência, a gente pode então trabalhar o método de discutir caso, a partir de uma troca de informações, de fato uma troca de saberes, aí tem técnicas para fazer isso. Quando a gente consegue fazer esse segundo movimento, aí eles já começam a não abrirem mais mão de discutir caso, aí até eles começarem a fazer uma ação coordenada nos casos graves para produzir 
um projeto terapêutico, eles estão vivenciando coisas e isso vai transformando o processo de trabalho da unidade toda, não só daquela equipe. Se a gente consegue trazer junto o gestor, a gente vai modificando, isso pode virar um espaço de tomada de decisão (20)

Sendo assim, sugere-se, sob a influência do movimento de humanização, a integralidade assistencial pode ser desenvolvida não, apenas, como superação de dicotomias técnicas entre preventivo e curativo, entre ações individuais e coletivas, mas respeitando e priorizando e tendo responsabilidade com a pessoa, com o profissional se dedicando a alguém de forma zelosa, como uma forma de superar os lados dessa dicotomia. Ou seja, a humanização instiga a pensar que não é possível equacionar a questão da integralidade sem valorizar um encontro que vai além de saberes técnicos e de uma "oferta organizada" de serviços. A integralidade do cuidado deixa de ser, portanto, a simples junção de atividades preventivas e curativas, individuais e coletivas, passa a dar lugar aos diferentes saberes e práticas, enfatiza a importância dos cuidados prestados pelos profissionais. Integralidade e humanização do cuidado reúnem, portanto, em um mesmo novo princípio, uma nova tendência de reconhecimento do outro, um direcionamento da materialização do direito à saúde que não é mais a simples soma aritmética de aspectos técnicos das ações de saúde (24).

Cabe buscar estratégias que, levem em conta os motivos pelos quais as pessoas procuram os serviços de saúde e não produzir barreiras e nem deixar sem respostas o sofrimento das pessoas. Em relação a isso, vale ressaltar que há pouco conhecimento sobre o sofrimento provocado pelas práticas de cuidado e pelos arranjos dessas práticas. Não basta garantir o acesso integral aos brasileiros. As práticas devem estar fortemente voltadas para dar resposta ao sofrimento das pessoas ou para evitar esse sofrimento. Esse é o desafio de todas as políticas que estão voltadas especificamente para as transformações das práticas. Esse também é o desafio da política de humanização (5).

\section{A potência do Humanizasus para efetivação da integralidade}

Não basta que tenhamos somente uma Constituição bem escrita para que seja cumprida e obedecida, existe a possibilidade de travarmos uma batalha, pelas vias do direito e baseado na Constituição para que seja possível melhorar as condições sociais, através da garantia do exercício dos direitos individuais e de cidadania a todos, da forma 
mais completa possível. Nesse sentido, uma norma jurídica bem elaborada pode ser um instrumento de grande relevância para a melhoria social (27).

As políticas públicas, ao contrário das leis, não são gerais e abstratas, mas são elaboradas para a realização de objetivos específicos. Princípios são proposições que descrevem direitos; políticas são proposições que descrevem objetivos.

A função da PNH é, [pois], a partir do que está dito do que deve ser feito lá nos princípios e diretrizes do SUS. é criar maneiras de como fazer, de tornar concreto, então. O nosso compromisso é dizer como ofertar maneiras de fazer com que, por exemplo, a integralidade se efetive. Então, o que a gente faz? A gente apoia alguma experiências do SUS, alguns municípios, alguns hospitais, algumas redes, faz processo de formação, para a gente pegar experiência, sistematizar, fazer dela uma proposta técnica reproduzível em outros lugares, e ai a gente sai ofertando. A gente já descobriu que para organizar um hospital, a gente precisa fazer um colegiado; para se fazer acolhimento, é preciso ter um colegiado de urgência e emergência, porque todas as experiências que deram certo fizeram por aí; para o acolhimento acontecer, para as coisas funcionarem e 0 trabalhador se sentir compromissado e participante desse processo, que é preciso ter um conselho gestor, que o usuário participe para poder ter visita aberta ao hospital, que é um dos direitos do usuário, e que garante a integralidade. Então essa relação do que está prescrito. do que fazer para chegar na ação concreta e ver acontecendo nos serviços (...) os princípios, você tem um caminho que é o como se faz isso. A PNH é uma política para produzir esse como e pautar as outras políticas com esses dispositivos (20).

De acordo com suas características especiais de fazer presente em todas as práticas sanitárias, por diversas vezes a Política de Humanização estará se efetivando e consolidando através das próprias ações de rotina dos serviços, agregando os princípios da humanização nos passos da produção desses serviços. Como exemplo, temos o acolhimento com avaliação de risco, procurando-se imprimir uma marca da humanização que reorienta a abordagem da população, dando prioridade aos casos de acordo com sua gravidade e ofertando mecanismos adequados de respostas (21).

Para exemplificar esse modus operandi, Nunes (20) detalhou:

Então, quando (...) uma das nossas diretrizes é o acolhimento, a gente entende que acolhimento é uma diretriz que orienta como a gente pode produzir com equidade, integralidade e universalidade; co-gestão, a mesma coisa; então, todas as diretrizes da PNH (...) vão nesse sentido e elas apontam caminhos". No caso do acolhimento, "a gente entende que acolhimento é uma diretriz que orienta, que a entrada do usuário no sistema de saúde não pode se restringir a um regime de portaria, então (...) acolher é a gente ter um sistema único de saúde que amplie cada vez mais e facilite o acesso e que esse acesso não se dê só lá na porta de entrada, na 
atenção básica, na urgência e emergência, mas que seja um contínuo acesso, que seja um processo de acessibilidade, que ele entre, permaneça e transite dentro do sistema de saúde, na rede, na linha de cuidado, no sentido de ter suas necessidades atendidas integralmente, que ele possa participar e fazer uso e constituir um itinerário dentro do sistema de saúde.

Aí, um dos dispositivos que concretizam as diretrizes, o acolhimento, é o acolhimento com classificação de risco, então é não ter a fila, essa fila não ser orientada por ordem de chegada, ser orientada por vulnerabilidade e risco, que é principio da equidade; que seja organizado de tal forma que as pessoas consigam expressar, a partir de suas demandas, suas necessidades de saúde e que as equipes e os equipamentos de saúde do SUS sejam capazes de fazer uma escuta qualificada, ou seja, transformar essas demandas em necessidades de saúde (...) (20)

Os dispositivos da humanização são de extrema importância desde que sejam operacionalizados de forma efetiva. Dependem de complexos processos de implantação, enfrentando fatores favoráveis e desfavoráveis, sendo importante a participação de diversos atores. Podemos citar os dispositivos da gestão de serviços, onde são compostos os Conselhos ou Colegiados de gestão, valorizando a participação dos atores, o trabalho em equipe, a chamada, "comunicação lateral" e democratizando os processos decisórios, com a participação de gestores, trabalhadores e usuários, assumindo a responsabilidade pelas mudanças de forma igualitária (6).

Em síntese, segundo Nunes (20):

o conjunto das diretrizes aponta para dispositivos, então cada diretriz aponta para um conjunto de possibilidades concretas de organização do trabalho, de dispositivos de cuidado; o projeto terapêutico é uma proposta técnica, uma forma de organizar a relação de equipe para produzir o cuidado que produz mais integralidade. O projeto terapêutico então, na política de humanização, é um dispositivo de ampliação da clinica, de cogestão, de acolhimento e de defesa dos direitos dos usuários. (...) É difícil hoje você conversar com o trabalhador ou o usuário que não considera a questão da humanização uma questão importante. A gente tem umas experiências muito bem consolidadas que demonstram isso: olha aqui, este hospital [referindo-se a um Hospital genérico], ele é um exemplo do que a gente está dizendo, do que deveria ser a humanização. A gente tem esses exemplos, e aí isso vai gerando esse efeito demonstrativo. Essa pauta vem crescendo e vem já numa consistência de trazer esses princípios e diretrizes, ao ser aquela coisa de reunir, colocar os palhacinhos para fazer brincadeiras com as crianças, que tem sua importância, mas não se trata do que a gente está dizendo aqui, nós estamos falando de mudanças de processo organizacionais, de gestão, da relação entre trabalhadores e usuários, da questão da participação social, da força de trabalho, da democracia institucional. 


\section{Considerações finais}

É importante destacar que as lutas em favor dos direitos sociais são de extrema importância, com destaque ao direito à saúde, que para que seja efetivado depende de uma série de outros direitos. A Constituição brasileira permitiu a formação de um modelo para o sistema de saúde, porém outras medidas devem transformar o dia a dia das organizações e do trabalho em saúde. Dentre elas, a formulação de políticas públicas, que devem ser pensadas para que se possam alcançar os princípios propostos pela Constituição.

Uma questão que deve ser levantada e que pode colocar a efetividade do SUS em questionamento, e juntamente com ele o direito á saúde, diz respeito ao descontentamento e descrédito dos usuários em relação aos serviços de saúde. Este artigo procurou colocar em debate como a Política de humanização pode contribuir para a criação de possibilidades de induzir transformações para manter em aberto a abrangência do direito à saúde, colocando em ênfase o atendimento integral, e orientando a execução dessa política para além dos limites da estrutura social e das relações sociais vigentes.

Todas as lutas impostas no âmbito da saúde pública estão resultando em uma série de medidas cujo objetivo é o oferecimento de uma assistência com qualidade, que atenda com respeito e cuidado às necessidades dos usuários de saúde. A PNH é fruto recente dessas lutas, buscando uma condição diferente da atual, onde seja possível fornecer uma assistência melhor, com a participação efetiva de gestores, profissionais e usuários.

A questão levantada sobre a integralidade da atenção à saúde busca configurar esse princípio como eixo estruturante da necessidade de mudança a partir de políticas públicas de saúde, dos serviços, suas práticas, e também dos profissionais de saúde que diante disso poderão defender um modelo de atenção à saúde fundamentado no princípio da integralidade, no qual o relacionamento com usuário seja feito de forma a percebê-lo como sujeito e não como um objeto. A integralidade pode ser considerada como um princípio orientador das práticas de saúde, da organização do trabalho, bem como, da organização das políticas.

Consideramos que a PNH representa um avanço em relação ao campo político, onde as práticas de saúde não se resumem apenas uma dimensão técnica abrange a dimensão relacionada as práticas sociais complexas, passando pelas dimensões culturais, 
econômicas, políticas e especialmente ideológicas. Essa política abre a visão de gestores, trabalhadores e usuários para novos valores, conceitos, significados e perspectivas de maneira diferente, que compõem o âmbito das relações humanas e da produção de subjetividade. Outro ponto relevante que foi possível observar versa a respeito da importância de se obter espaços e condições de trabalho favoráveis para promover a inovação e diversificação das ações que são historicamente praticadas em relação à promoção da saúde. Para isso, é de suma importância o apoio e adesão dos gestores, bem como a participação dos usuários, na prática do controle social, atuando como protagonistas dos processos de formulação e implementação de ações de saúde.

Deste modo, o processo de construção da consciência sanitária passa pela superação das barreiras e limitações, tanto no campo das políticas púbicas, como no campo das instituições de atendimento e no modelo assistencial, mas de maneira especial no campo das idéias. Esse ponto tem um papel estratégico no processo de mudança social, contribuindo para gerar novos significados por parte dos usuários, acerca de seus direitos, e de seu papel como agente de mudanças no sistema.

\section{Referências}

1. Brasil. Constituição da República Federativa do Brasil de 1988. Brasília: Senado Federal, 2008.

2. Baptista, TWF. História das políticas de saúde no Brasil: a trajetória do direito à saúde. In: Matta, GC; Pontes, ALM. (Orgs). Políticas de saúde: organização do Sistema Único de Saúde. Rio de Janeiro: EPSJV/Fiocruz, 2007, p.29-60.

3.Traverso-Yépez, M; Morais, NA. Reivindicando a subjetividade dos usuários da Rede Básica de Saúde: para uma humanização do atendimento. In: Caderno de Saúde Pública. Rio de Janeiro, 20 (1):80-88. 2004

4.Brasil. Lei no 8.080, de 19 de setembro de 1990. Disponível em: <http://www.saude.df.gov.br/legislacao_sus/leis)Lei-8080.html> [Acesso em: 26 out 2012].

5.Mattos, RA. Os sentidos da integralidade: algumas reflexões acerca dos valores que merecem ser defendidos. In: Pinheiro, R; Mattos, RA (org.) Os sentidos da integralidade. Rio de Janeiro: IMS/UERJ/ABRASCO, 2001, p. 39-64.

6.Ministério da Saúde. HUMANIZASUS: política nacional humanização, 2004.

7.Ministério da Saúde. Política Nacional de Humanização da Atenção e Gestão da Saúde. Projeto do Curso de formação de apoiadores para a PNH. Brasília, 2006. 
8.Rizzotto MLF. As políticas de saúde e a humanização da assistência. In: Revista Brasileira de Enfermagem, 55 (2): 196-99. 2002

9.Fortes, PAC. Ética, direitos dos usuários e políticas de humanização da atenção à saúde. In: Saúde e Sociedade. 13 (3):30-35. 2006

10.Conill, EM. Avaliação da integralidade: conferindo sentidos para os pactos na programação de metas dos sistemas municipais de saúde. In: Caderno de Saúde Pública. 20: 1417-23, 2004.

11.Fleury, S. Reforma sanitária brasileira: dilemas entre o instituinte e o instituído. In: Ciência \& Saúde Coletiva. 14 (3): 743-752, 2009

12. Camargo JR, KR. As muitas vozes da integralidade. In: Pinheiro. R.; Mattos. RA, (prgs). Os sentidos da integralidade na atenção e no cuidado à saúde. Rio de Janeiro: Universidade do Estado do Rio de Janeiro/ABRASCO, 2006, p.13-17.

13.Ministerio da Saúde. Grupo Técnico da Comissão Intergestores Tripartite. Diretrizes para Organização das Redes de Atenção à Saúde do SUS. 2010. Disponível em:< http://portal.saude.gov.br/portal/arquivos/pdf/2b_221210.pdf>. [Acesso em: 2 dez.2012]

14. Fontoura, RT; Mayer, CN. Uma breve reflexão sobre a integralidade. In: Revista Brasileira de Enfermagem. 59 (4): 532, 2006.

15.Casate, JC; Correa, AK. Humanização do Atendimento em Saúde:conhecimento veiculado na literatura brasileira de enfermagem. In: Revista Latino-americana de Enfermagem, 13 (2): 105-11. 2005, p.

16. Maia, C. Guilhem, D.; Lucchese, G. Integração entre vigilância sanitária e assistência da mulher: um estudo sobre a integralidade no SUS. In: Caderno de Saúde Pública, Rio de Janeiro, 26 (4):682-692, 2010.

17.Vaitsman, J; Andrade, GRB. Satisfação e responsividade: formas de medir a qualidade e a humanização da assistência à saúde. In: Ciência \& Saúde Coletiva, 10 (3):599-613. 2005

18. ONU. Declaração Universal dos Direitos do Homem, 1948. <http://www.oas.org/dil/port/ 1948\%20Declara\%C3\%A7\%C3\%A30\%20Universal\%20dos\%20Direitos\%20Humanos.pdf> [acesso em: 10 nov 2012].

19. Sousa, WS; Moreira, MCN. A temática da humanização na saúde. In: Comunicação Saúde Educação, 12 (25):327-38, 2008.

20. Nunes, GO. Aspectos sobre o HUMANIZASUS. Ministério da Saúde. Brasília, 30 de Novembro de 2012. Entrevista concedida a autora 
21. Santos - Filho, SB Perspectivas na Avaliação na Política Nacional de Humanização em Saúde: aspectos conceituais e metodológicos. In: Ciência \& Saúde Coletiva, 12 (4): 999 - 110, 2007.

22.Kunkel, MB. Humanização na saúde: o caminho para o SUS. In: FERLA, A; Fagundes, S. (Orgs). Tempo de inovações: a experiência da gestão na saúde do Rio Grande do Sul, Porto Alegre. Dacasa/Escola de Saúde Pública, 2002, p. 195-2002.

23. Jean-Arnaud, A. Capeller, W. Cidadania e direito à saúde. In: O Direito achado na rua: Introdução crítica ao direito à saúde. Brasília: CEAD/ UnB, 2008, p. 31-4

24. Puccini, PT; Cecílio, LCO. A humanização dos serviços e o direito à saúde. In: Caderno de Saúde Pública, 20(5):1342-1353, 2004.

25. Delduque, MC. Oliveira. MSC. Tijolo por tijolo: a construção permanente do direito à saúde. In: O Direito achado na rua: Introdução crítica ao direito à saúde. Brasília: CEAD/ UnB, 2008, p. 103-111.

26. Sousa, WS; Moreira, MCN. A temática da humanização na saúde. In: Comunicação Saúde Educação, 12 (25):327-38, 2008.

27. Bucci, MPD. Buscando um conceito de Políticas Públicas para a concretização dos Direitos Humanos. In: Direitos humanos e políticas públicas. São Paulo, 2001, p. 5-17. 